2017-10-02

\title{
A Mathematical Analysis of Drug Dissolution in the USP Flow Through Apparatus
}

\author{
David McDonnell \\ Technological University Dublin, david.mcdonnell@tudublin.ie \\ Deirdre M. D'Arcy \\ Trinity College Dublin, Ireland \\ Lawrence J. Crane \\ Institute for Numerical and Computational Analysis
}

See next page for additional authors

Follow this and additional works at: https://arrow.tudublin.ie/engschmecart

Part of the Fluid Dynamics Commons, and the Pharmaceutics and Drug Design Commons

\section{Recommended Citation}

McDonnell, David; D'Arcy, Deirdre M.; Crane, Lawrence J.; and Redmond, Brendan, "A Mathematical Analysis of Drug Dissolution in the USP Flow Through Apparatus" (2017). Articles. 49.

https://arrow.tudublin.ie/engschmecart/49

This Article is brought to you for free and open access by the School of Mechanical and Design Engineering at ARROW@TU Dublin. It has been accepted for inclusion in Articles by an authorized administrator of ARROW@TU Dublin. For more information, please contact arrow.admin@tudublin.ie, aisling.coyne@tudublin.ie, gerard.connolly@tudublin.ie.

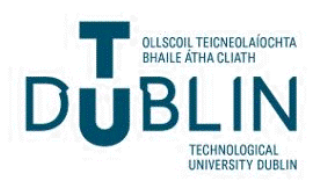




\section{Authors}

David McDonnell, Deirdre M. D'Arcy, Lawrence J. Crane, and Brendan Redmond 


\title{
A Mathematical Analysis of Drug Dissolution in the USP Flow Through Apparatus
}

\author{
David McDonnell · D.M D'Arcy · L.J Crane - Brendan Redmond
}

\begin{abstract}
This paper applies boundary layer theory to the process of drug dissolution in the USP (United States Pharmacopeia) Flow Through Apparatus. The mass transfer rate from the vertical planar surface of a compact within the device is examined. The theoretical results obtained are then compared with those of experiment. The paper also examines the effect on the dissolution process caused by the interaction between natural and forced convection within the apparatus and the introduction of additional boundaries.
\end{abstract}

Keywords Drug Dissolution · USP Flow Through Apparatus · Mass Transfer - Boundary Layer Theory

\section{Introduction}

Historically, much work has been conducted in mathematically modeling processes involving heat transfer. Recently, work by McDonnell et al[1,2,3] has taken some of these models and adapted them to instead model mass transfer. This paper takes these adapted models and applies them to the process of drug dissolution in the USP Flow Through Apparatus. This section gives

D. McDonnell

School of Mechanical and Design Engineering, Dublin Institute of Technology, Bolton St, Dublin 1, Ireland.

Tel.: +353-863667487

E-mail: david.mcdonnell@dit.ie

D.M. D'Arcy

School of Pharmacy and Pharmaceutical Sciences, Trinity College Dublin, Dublin 2, Ireland.

\section{L.J. Crane}

Institute for Numerical Computation and Analysis, 7-9 Dame Court, Dublin 2, Ireland.

\section{B. Redmond}

School of Mathematical Sciences, Dublin Institute of Technology, Kevin St, Dublin 8, Ireland. a brief introduction to the apparatus and to some experimental work that has been conducted by several authors.

\subsection{Drug Dissolution Testing}

Dissolution testing is a very important area of research within the pharmaceutical industry. The ability to produce drugs with a given dissolution rate will lead to improved performance in the treatment of patients and will be of economic benefit to the pharmaceutical industry. However, dissolution testing in laboratories, aimed at reflecting in vivo conditions, can be both time consuming and costly. A mathematical model of the process would serve to alleviate some of these costs.

Currently, most testing of drug dissolution rates take place in standardized USP apparatuses[4]. A number of these apparatuses exist, and it is the aim of this paper to analyse drug dissolution in the USP Flow Through Apparatus.

\subsection{The USP Flow Through Apparatus}

The USP Flow Through Apparatus consists of four main elements; a reservoir, a pump, the flow through cell and a bath. The reservoir holds the dissolution medium which is then forced through the flow through cell, shown in figure (1), by the pump. The pump typically delivers volumetric flow rates of between 4 and 16 $\mathrm{mL}$ per minute, although larger flow rates are achievable. Apparatuses which deliver semi- sinusoidal and full-sinusoidal pulsing flow profiles, or non pulsing flow, are available. Pulsing flow is delivered at 120 pulses per minute The water bath is used to maintain a constant temperature within the flow through cell. 


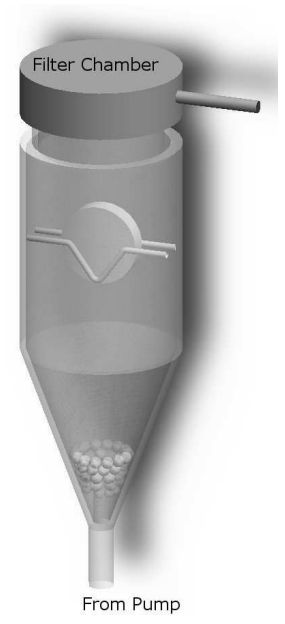

Fig. 1 The USP Flow Through Cell

The flow through cell is where the compact is housed. The cell is a cylindrical vessel with a conical base. The cone part of the vessel is usually filled with small glass beads to promote laminar flow. The compact may be positioned vertically in a tablet holder located half-way up the cell. Two cell sizes are available; a large cell of diameter $22.6 \mathrm{~mm}$ and a small cell with a diameter of $12 \mathrm{~mm}$.

\subsection{Experimental Work}

Some recent research in the area of pharmaceutical dissolution testing has focused on the process of drug dissolution in the Flow Through Apparatus. Many commentators, including Beyssac et al[5], Singh et al[6] and Fotaki[7], suggest that the apparatus holds a number of advantages over some of its predecessors, including the USP Paddle Apparatus. The flow through cell controls the placement of the compact better than the Paddle Apparatus and, also, the hydrodynamics of the system are more clearly defined. The flow through cell can also be used in an open configuration, which according to Singh et al[6], makes it possible to maintain sink conditions. This can better mimic the gastrointestinal tract if absorption is not the rate limiting step. They note that this is of particular importance for poorly soluble drugs. Finally, the Flow Through Apparatus allows for the dissolution media to be changed over the course of an experiment. This creates a more realistic recreation of in-vivo conditions as a dosage form passes through different regions of the gastrointestinal tract and can help with the development of in vitro-in vivo correlations (Fotaki[7]).

Experiments have been conducted by D'Arcy et al $[8,9,10]$ in the large flow through cell using non disinte- grating compacts composed of benzoic acid, and with a diameter of $13 \mathrm{~mm}$. The experiments were conducted for different flow rates including when the pump is idle and the flow is that of pure natural convection. The natural convection case was performed outside the flow through cell in a so called Free Convection System, as illustrated in figure (3). The results of these experiments have shown that, in some cases, an increase in the flow rate has resulted in a decrease in the dissolution rate from the surface of the compact. Similar results have also been reported by Cammarn and Sakr[11], who state that in certain cases an increase in flow rate resulted in no increase in the dissolution rate.

\subsection{Initial Observations}

The process of drug dissolution in the USP Flow Through Apparatus can be set up as a boundary layer problem. The obvious approach is to first look at the case in which the pump is idle (i.e. no upward flow). This case is one of natural convection only in which the flow, and hence the dissolution process, will be driven purely by buoyancy effects.

The mathematical model used by McDonnell et al[1] to study this natural convection process is analogous to that of heat transfer due to natural convection for large Prandtl numbers, for which an exact solution exists due to Kuiken[12]. The approach taken involves dividing the problem into two regions: a thin region close to the wall in which buoyancy effects dominate and a much thicker outer region in which buoyancy effects may be neglected. In the case of mass transfer, the inner region is one of natural convection only in which the velocity is generated by the weight of dissolved particles. A similarity solution is obtained for this inner layer, at which point the outer layer is treated as one of forced convection in which the velocity is generated solely by its contact with the inner layer. For liquids, the non-dimensional mass transfer coefficient, known as the Schmidt number $\left(S_{c}\right)$, is large. Consequently, the concentration boundary layer is an order of magnitude thinner than the momentum layer.

Having examined the case of pure natural convection, McDonnell et al[1] introduce a perturbation term to the stream function to model a constant counterflow. In a reversal of the case of Kuiken[12], the outer layer is treated first with its solution then matched into the inner layer. This counterflow may be used to model the effect that the pump has at relatively small upward velocities, where the upward velocity does not penetrate the downward flow due to natural convection, but rather flows around it. 
Finally, McDonnell[2] has developed a Pohlhausen solution that mimics the natural convection case outlined above. This Pohlhausen solution is then amended to model the introduction of a perpendicular surface. Throughout the analysis values for the saturation concentration, $C_{s}$, coefficient of diffusion, $D$, and the kinematic viscosity, $\nu$, are taken to be $4.564 \times 10^{-3} \mathrm{~g} / \mathrm{cm}^{3}$, $1.236 \times 10^{-5} \mathrm{~cm}^{2} / \mathrm{s}$ and $0.7 \times 10^{-2} \mathrm{~cm}^{2} / \mathrm{s}$ respectively. These values correspond to benzoic acid dissolving in $0.1 \mathrm{M} \mathrm{HCl}$, as reported by D'Arcy et al[8].

\subsection{Aim of Paper}

The primary aim of this research is to accurately predict drug dissolution rates from the vertical planar surface of a benzoic acid compact within the USP Flow Through Apparatus. The approach used is to apply well documented analytical techniques with specific modifications relevant to the apparatus. These modifications are introduced to model the effect of the pump, the effect of the introduction of additional boundaries (tablet holder and jar lid in free convection system) and the interaction between natural and forced convection processes. The research also aims to show that for compounds with relatively low solubility,such as benzoic acid, the dominant mass transfer mechanism within the apparatus is that of natural convection, with forced convection mainly providing a deceleration or disruptive effect. Finally, the research shows that in order for forced convection to dominate, the pump would have to provide extremely large volumetric flow rates that are well above normal operational conditions.

\section{Mathematically Modeling Flow in the USP Flow Through Apparatus}

2.1 Mass Transfer from a Vertical Flat Surface due to Natural Convection

The case of heat transfer from the surface of a vertical flat plate for large Prandtl numbers was studied by Kuiken[12]. This case has been adapted by McDonnell et al[1] to model mass transfer from the flat surface of a soluble material for large Schmidt numbers. McDonnell et al[1] state that for such a flow the maximum downward velocity due to natural convection may be calculated by:

$U_{\max }=\left[\frac{g C_{s} x}{\rho S_{c}}\right]^{\frac{1}{2}}$.

where $x$ is the vertical distance from the leading edge, $g$ is acceleration due to gravity, $\rho$ is the density of the solvent, $C_{s}$ is the saturation concentration and $S_{c}$ is the non-dimensional Schmidt number. Using equation (1), it is easily shown that for a benzoic acid compact dissolving in $0.1 \mathrm{M} \mathrm{HCl}$ the upward flow generated within the flow through cell is relatively small compared to the downward natural convection flow generated by the weight of solution containing the dissolved drug. As such, natural convection may be thought of as the dominant mass transfer mechanism within the apparatus. For the case of pure natural convection, McDonnell et al[1] give the flux per unit width as

Flux $=0.948 D C_{s}\left[\frac{g C_{s}}{4 D \rho \nu}\right]^{\frac{1}{4}} x^{\frac{3}{4}}$,

where $D$ is the coefficient of diffusion of the soluble material and $\nu$ is the kinematic viscosity of the dissolution medium.

2.2 Mass Transfer from a Vertical Flat Surface with a Constant Counterflow

The previous section outlines the case of mass transfer due to natural convection as presented by McDonnell et al[1]. In the same work, this pure natural convection model is expanded to include a constant counterflow. For the case of small upward velocities, McDonnell et al[1] have shown that this upward flow will not penetrate the natural convection boundary layer formed and will instead flow around it, having a deceleration effect. This model may be applied to the flow through cell, in which only relatively small upward velocities are generated. For the case of natural convection with a counterflow, the flux per unit width is given as:

$$
\begin{aligned}
\text { Flux }=0.948 D C_{s}\left[\frac{g C_{s}}{4 D \rho \nu}\right]^{\frac{1}{4}} x^{\frac{3}{4}} \\
\times\left[1-0.76\left[\frac{U_{0}^{2} \rho S_{c}}{g C_{s} x}\right]^{\frac{1}{2}}\right],
\end{aligned}
$$

where $U_{0}$ is the velocity of the counterflow.

2.3 Natural Convection Flow on a Vertical Flat Surface with a Perpendicular Surface

Another mathematical model of interest is that of natural convection with the introduction of a surface which lies perpendicular to the main direction of flow. Two cases are presented by McDonnell[2]; natural convection flow approaching a perpendicular surface and natural convection flow developing at a stagnation point. Both of these models are approximate solutions using 
a Pohlhausen integral method based on the work of Squire[13].

For the case of natural convection approaching a perpendicular surface, McDonnell[2] adapts the velocity profile of Squire[13] to model pure natural convection for large Schmidt numbers. This adapted method is found to approximate the exact solution to within $2 \%$ (McDonnell[2]). To model the introduction of a perpendicular surface, the velocity profile is again amended, this time based on a family of solutions produced by Tani[14] and Howarth[15]. The flux per unit width is given by

Flux $=2 D C_{s} \int_{0}^{x} \frac{1}{\delta_{c}} d x$.

where $\delta_{c}$ is the concentration boundary layer thickness and must be found by solving the ordinary differential equation:

$\frac{d \delta_{c}}{d x}=\frac{23.085 D}{A \delta_{c} x^{\frac{1}{2}}}\left[\frac{L}{L-x}\right]-\frac{\delta_{c}}{2 x}+\frac{\delta_{c}}{[L-x]}$,

where $A=4 D\left[\frac{g C_{s}}{4 D \rho \nu}\right]^{\frac{1}{2}}$ and $L$ is the vertical distance at which the perpendicular surface lies. The total flux per unit width is given as

$$
\begin{array}{rl}
\text { Flux }=0.7 & 05 D C_{s}\left[\frac{g C_{s}}{4 D \rho \nu}\right]^{\frac{1}{4}} x^{\frac{3}{4}} \\
\times & {\left[1.333-0.4\left(\frac{x}{L}\right)-0.06\left(\frac{x}{L}\right)^{2}-\ldots\right] .}
\end{array}
$$

The case of natural convection developing at a stagnation point is also an adaptation of the Pohlhausen method presented by Squire[13]. The flux per unit width is given as

Flux $=0.6751 D C_{s}\left[\frac{g C_{s}}{4 D \rho \nu}\right]^{\frac{1}{4}} x^{\frac{3}{4}}\left[\frac{x}{x_{\max }}\right]^{\frac{1}{2}}$.

where $x_{\max }$ is the length of the vertical surface. Both of these models include a perpendicular surface which inhibits the natural convection flow and as such result in decreases in mass transfer rates of between 30 and $40 \%$, when compared with that of pure natural convection only.

2.4 Mass Transfer from a Vertical Flat Surface due to a Constant Upward Flow

Finally, the case of mass transfer due to an upward flow is examined. In this case, mass transfer occurs due to an upward flow, leading to an increase in density of the dissolution medium close to the surface. At some height along the surface the weight of solution containing the dissolved drug counteracts the upward force causing boundary layer separation. McDonnell et al[3] have examined this case using a modified flat plate Blasius flow based on the work of Lévêque[16]. The flux per unit width is given as

$$
\begin{aligned}
\text { Flux }=0.2625 & {\left[\frac{D C_{s} \rho U_{\infty}^{3} \tilde{X}}{g}\right]^{\frac{1}{2}} } \\
& \times\left[1.33-0.314 \tilde{X}-0.095 \tilde{X}^{2}+\ldots\right]^{\frac{2}{3}},
\end{aligned}
$$

where $\tilde{X}$ is related to the point of separation and given as $\tilde{X}=9\left[\frac{\Gamma\left(\frac{2}{3}\right)}{\Gamma\left(\frac{1}{3}\right)}\right]\left[\frac{g C_{s} x}{\rho U_{0}^{2}}\right]\left[\frac{1}{S_{c}}\right]^{\frac{1}{3}}$. The point of separation for this flow occurs at $\tilde{X}=0.5$. Also, $\Gamma\left(\frac{2}{3}\right)$ and $\Gamma\left(\frac{1}{3}\right)$ are the values of the gamma function for $\left(\frac{2}{3}\right)$ and $\left(\frac{1}{3}\right)$ respectively.

\section{Application to Drug Dissolution in the USP Flow Through Apparatus}

In this section, the dissolution rate from the vertical flat surface of a compact in the USP Flow Through Apparatus is analysed. The apparatus may be assembled using either a large $22.6 \mathrm{~mm}$ diameter flow through cell or a smaller $12 \mathrm{~mm}$ cell (see figure (1)). The pump delivers a flow with a semi-sinusoidal profile, with typical volumetric flow rates of between 4 and $16 \mathrm{~mL} / \mathrm{min}$. For the purpose of estimating the dissolution rate from the surface, a time averaged constant upward flow is taken in place of this semi-sinusoidal profile, for the period over which the pump is active. Experimental

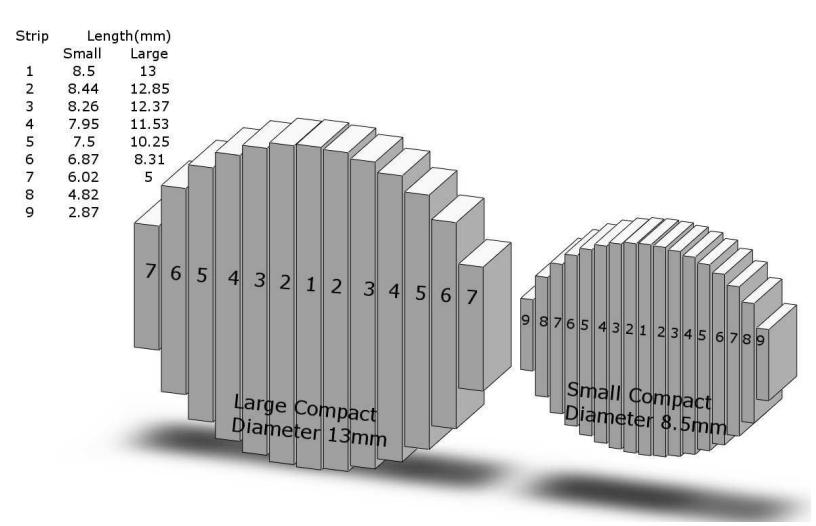

Fig. 2 Surface Strips for Large and Small Compacts

results for the dissolution rates from the surface of a 
compact have been produced by D'Arcy et al[10]. In these experiments a compact of $8.5 \mathrm{~mm}$ in diameter is used in the smaller flow through cell and a compact of $13 \mathrm{~mm}$ in diameter used for the larger cell, both with an approximate height of $3 \mathrm{~mm}$. In order to apply the mathematical models discussed in the previous sections to the surface of the compact, the surface is divided into strips of $1 \mathrm{~mm}$ for the larger compact and $0.5 \mathrm{~mm}$ for the smaller compact. This is illustrated in figure (2). Wherever available, the results are compared with those of experiment, as reported by D'Arcy et al[10].

3.1 Dissolution Rates in the USP Flow Through Apparatus: Pump Idle

For the case of natural convection only, the flux per unit width for each strip is taken from equation (2) to be

Flux $=0.948 D C_{s}\left[\frac{g C_{s}}{4 D \rho \nu}\right]^{\frac{1}{4}} x^{\frac{3}{4}}$,

where $x$ is the length of the strip. The maximum downward velocity due to natural convection for each individual strip is calculated as

$U_{\max }=\left[\frac{g C_{s} x}{\rho S_{c}}\right]^{\frac{1}{2}}$.

The maximum downward velocities for both the large and small compacts are shown in table (1). Equation

Table 1 Maximum Downward Velocity: Natural Convection

\begin{tabular}{ccc}
\hline $\begin{array}{c}\text { Strip } \\
\text { Number }\end{array}$ & $\begin{array}{c}\text { Large Cell } \\
\text { Velocities }(\mathrm{cm} / \mathrm{s})\end{array}$ & $\begin{array}{c}\text { Small Cell } \\
\text { Velocities }(\mathrm{cm} / \mathrm{s})\end{array}$ \\
\hline 1 & 0.101 & 0.082 \\
2 & 0.101 & 0.082 \\
3 & 0.099 & 0.081 \\
4 & 0.096 & 0.079 \\
5 & 0.090 & 0.077 \\
6 & 0.081 & 0.074 \\
7 & 0.063 & 0.069 \\
8 & $N / A$ & 0.062 \\
9 & $N / A$ & 0.048 \\
\hline
\end{tabular}

(9) is applied to the flat surface of both the large and small compacts, the results of which are shown in table (2). D'Arcy et al[10] report that for the case of natural convection the experiment is conducted using a so called Free Convection System, as illustrated in figure (3). The introduction of this additional boundary, namely the jar lid, may not be ignored. As such the flow in such a system would be better modeled by natural convection flow developing at a stagnation point,

\section{Free Convection System}

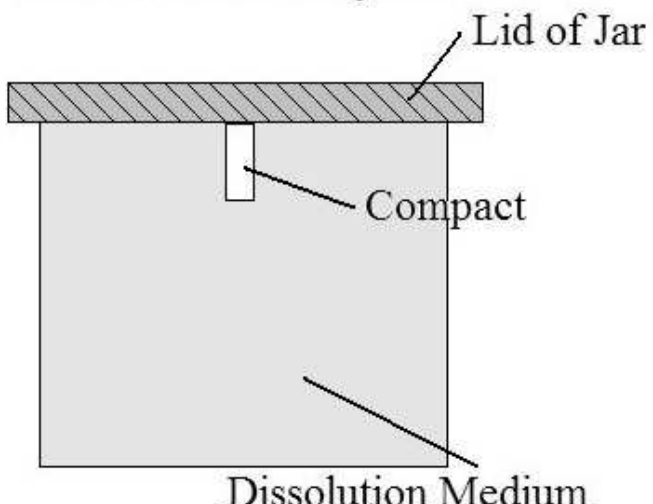

Fig. 3 Free Convection System

as outlined by McDonnell[2] and discussed in section (2.3). In this instance, the flux per unit width for each strip is taken from equation (7) to be

Flux $=0.6751 D C_{s}\left[\frac{g C_{s}}{4 D \rho \nu}\right]^{\frac{1}{4}} x^{\frac{3}{4}}\left[\frac{x}{x_{\max }}\right]^{\frac{1}{2}}$.

The results for this case are also displayed in table (2).

Table 2 Dissolution Rates: Natural Convection

\begin{tabular}{cc}
\hline $\begin{array}{c}\text { Compact } \\
\text { Diameter }(\mathrm{mm})\end{array}$ & $\begin{array}{c}\text { Predicted Dissolution } \\
\text { Rate }(\mathrm{g} / \mathrm{s})\end{array}$ \\
\hline 8.5 & $1.996 \times 10^{-6}$ \\
13 & $4.166 \times 10^{-6}$ \\
13 & $2.958 \times 10^{-6}{ }^{1}$ \\
\hline
\end{tabular}

\subsection{Dissolution Rates in the USP Flow Through Apparatus: Small Upward Velocities}

This section analyses the dissolution rates from the vertical flat surface of a compact for small upward velocities. A small upward velocity may be classified as one that is less than $15 \%$ of the maximum downward velocity due to natural convection, as shown in table (1). For velocities of this magnitude the upward flow will not penetrate the concentration boundary layer formed due to natural convection and will instead have the effect of a slow moving counterflow. As such the flux per

1 Mathematical Model of Free Convection Jar System. 
unit width is taken from equation (3) to be

$$
\begin{aligned}
\text { Flux }=0.948 D C_{s}\left[\frac{g C_{s}}{4 D \rho \nu}\right]^{\frac{1}{4}} x^{\frac{3}{4}} \\
\times\left[1-0.76\left[\frac{U_{0}^{2} \rho S_{c}}{g C_{s} x}\right]^{\frac{1}{2}}\right],
\end{aligned}
$$

where $U_{0}$ is the velocity of the counterflow. Such small upward velocities exist in the large flow through cell at constant volumetric flow rates less than $6 \mathrm{~mL} / \mathrm{min}$ and in the small cell for velocities less than $2 \mathrm{~mL} / \mathrm{min}$. Equation (12) is applied to the surface of a compact for several small velocities and table (3) compares the results with that of natural convection.

Table 3 Dissolution Rates: Small Upward Velocities

\begin{tabular}{cc}
\hline $\begin{array}{c}\text { Volumetric Flow } \\
\text { Rate }(\mathrm{mL} / \mathrm{min})\end{array}$ & $\begin{array}{c}\text { Predicted Dissolution } \\
\text { Rate }(\mathrm{g} / \mathrm{s})\end{array}$ \\
\hline Large Cell & \\
\hline 0 & $4.166 \times 10^{-6}$ \\
2 & $3.981 \times 10^{-6}$ \\
4 & $3.795 \times 10^{-6}$ \\
6 & $3.609 \times 10^{-6}$ \\
\hline Small Cell & \\
\hline 0 & $1.996 \times 10^{-6}$ \\
0.5 & $1.898 \times 10^{-6}$ \\
1 & $1.800 \times 10^{-6}$ \\
\hline
\end{tabular}

3.3 Dissolution Rates in the USP Flow Through Apparatus: Large Upward Velocities

In section (2.4), mass transfer from a vertical flat plate due to a constant upward flow is outlined. This work by McDonnell et al[3] shows that for small velocities the boundary layer formed due to an upward flow separates due to the weight of solution containing dissolved drug. However, for sufficiently large upward velocities boundary layer separation will not occur across the height of the surface and the solution will approach that of horizontal flat plate flow. The criterion to prevent separation occurring is given by McDonnell et al[3] as $F_{r}>0.071$, where $F_{r}$ is the non-dimensional Froude number. The required upward velocity may be calculated using

$U_{0}=[g x]^{\frac{1}{2}} F_{r}$

For the small and large compacts in the USP Flow Through Apparatus, this translates to semi-sinusoidal volumetric flow rates of 215 and $945 \mathrm{~mL} / \mathrm{min}$ respectively. Such flow rates, although well outside normal operational limits, may be achievable within the small cell, however, highly unlikely within the large cell. As such, Table (4) shows the predicted dissolution rates from the vertical flat surface of a compact for several large flow rates within the small cell only. The flux per unit width is given by equation (8), which is

$$
\begin{aligned}
\text { Flux }=0.2625 & {\left[\frac{D C_{s} \rho U_{\infty}^{3} \tilde{X}}{g}\right]^{\frac{1}{2}} } \\
& \times\left[1.33-0.314 \tilde{X}-0.095 \tilde{X}^{2}+\ldots\right]^{\frac{2}{3}},
\end{aligned}
$$

where $\tilde{X}=9\left[\frac{\Gamma\left(\frac{2}{3}\right)}{\Gamma\left(\frac{1}{3}\right)}\right]\left[\frac{g C_{s} x}{\rho U_{0}^{2}}\right]\left[\frac{1}{S_{c}}\right]^{\frac{1}{3}}$.

Table 4 Dissolution Rates: Large Upward Velocities

\begin{tabular}{cc}
\hline $\begin{array}{c}\text { Volumetric Flow } \\
\text { Rate }(\mathrm{mL} / \mathrm{min})\end{array}$ & $\begin{array}{c}\text { Predicted Dissolution } \\
\text { Rate }(\mathrm{g} / \mathrm{s})\end{array}$ \\
\hline Small Cell & \\
\hline 250 & $3.510 \times 10^{-6}$ \\
300 & $4.499 \times 10^{-6}$ \\
400 & $6.082 \times 10^{-6}$ \\
500 & $8.103 \times 10^{-6}$ \\
\hline
\end{tabular}

3.4 Dissolution Rates in the USP Flow Through Apparatus: Intermediate Upward Velocities

The most interesting cases are those which involve intermediate velocities. In such instances the upward flow will penetrate the natural convection boundary layer; however, it will also separate under the weight of solution containing the dissolved drug at some distance, say $x_{\text {sep. }}$. This means that the rate of drug dissolution below this point may be calculated using equation (14), as in the previous section. Above the separation point the flow will be that of natural convection. However, this natural convection flow must also separate at the same height along the surface as the modified Blasius flow and will therefore behave like that of natural convection on a vertical flat plate approaching a perpendicular surface. This is illustrated in figure (4). This type of flow is outlined in section (2.3) and the flux per unit width is taken from equation (6), given as

$$
\begin{aligned}
\text { Flux }=0.7205 D C_{s}\left[\frac{g C_{s}}{4 D \rho \nu}\right]^{\frac{1}{4}} x^{\frac{3}{4}} \\
\times\left[1.333-0.4\left(\frac{x}{L}\right)-0.06\left(\frac{x}{L}\right)^{2}-\ldots\right] .
\end{aligned}
$$




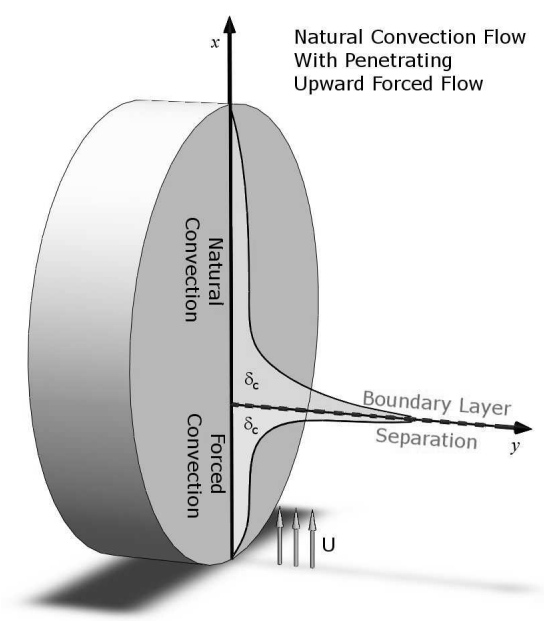

Fig. 4 Natural Convection Flow with Penetrating Upward Forced Flow

Table (5) shows the results for several intermediate velocities in both the small and large flow through cells.

Table 5 Dissolution Rates: Intermediate Upward Velocities

\begin{tabular}{ccc}
\hline $\begin{array}{c}\text { Volumetric } \\
\text { Flow Rate } \\
(\mathrm{mL} / \mathrm{min})\end{array}$ & $\begin{array}{c}\text { Predicted } \\
\text { Dissolution Rate } \\
(\mathrm{g} / \mathrm{s})\end{array}$ & $\begin{array}{c}\text { Predicted } \\
\text { Dissolution Rate } \\
(\mathrm{g} / \mathrm{s})\end{array}$ \\
\hline & Small Cell & Large Cell \\
\hline 4 & $1.617 \times 10^{-6}$ & $\mathrm{~N} / \mathrm{A}$ \\
8 & $1.620 \times 10^{-6}$ & $3.393 \times 10^{-6}$ \\
16 & $1.629 \times 10^{-6}$ & $3.394 \times 10^{-6}$ \\
32 & $1.667 \times 10^{-6}$ & $3.399 \times 10^{-6}$ \\
43 & $1.706 \times 10^{-6}$ & $3.404 \times 10^{-6}$ \\
50 & $1.737 \times 10^{-6}$ & $3.408 \times 10^{-6}$ \\
\hline
\end{tabular}

\subsection{Comparison with Experimentally Observed Data}

Table (6) compares a selection of predicted dissolution rates with those of experiment in the large flow through cell and a free convection system as reported by D'Arcy et al $[9,10]$. The predicted results exhibit some similarities to those of experiment in the sense that no significant increase in the mass transfer rate from the surface is recorded with increased volumetric flow rate. However, all the predicted dissolution rates appear to be much larger than the reported experimental dissolution rates.

Initially, especially for the case of natural convection alone, this result would seem to be somewhat disappointing since the model is well documented historically. However, D'Arcy et al[9] state that for the natural convection case the experiment is performed in a jar with the compact fixed to the inside of the lid. Such a
Table 6 Predicted versus Experimental Dissolution Rates for a $13 \mathrm{~mm}$ benzoic acid compact in the Large flow through cell

\begin{tabular}{ccc}
\hline $\begin{array}{c}\text { Volumetric } \\
\text { Flow Rate } \\
(\mathrm{mL} / \mathrm{min})\end{array}$ & $\begin{array}{c}\text { Predicted } \\
\text { Dissolution Rate } \\
(\mathrm{g} / \mathrm{s})\end{array}$ & $\begin{array}{c}\text { Experimental } \\
\text { Dissolution Rate } \\
(\mathrm{g} / \mathrm{s})\end{array}$ \\
\hline 0 & $4.166 \times 10^{-6}$ & $2.720 \times 10^{-6}{ }^{2}$ \\
8 & $3.393 \times 10^{-6}$ & $2.078 \times 10^{-6}$ \\
16 & $3.394 \times 10^{-6}$ & $2.101 \times 10^{-6}$ \\
43 & $3.404 \times 10^{-6}$ & $2.255 \times 10^{-6}$ \\
\hline
\end{tabular}

system may be better modeled by the case of a natural convection flow developing from a stagnation point, as outlined in section (2.3). If we apply this model to the surface of a compact the predicted rate of dissolution is $2.958 \times 10^{-6}$. This result is within $9 \%$ of the experimental result, which itself has a tolerance of about $\pm 3 \%$. Taking this information into account it is likely that the lid of the jar has a significant deceleration effect on the flow.

The predicted results for volumetric flow rates of 8,16 and $43 \mathrm{~mL} / \mathrm{min}$ would also seem to be overestimates when compared with those of experiment. These experiments were performed in the large flow through cell in which the compact is suspended about half way along the height of the cell. It would therefore not seem that any additional boundary was present that would account for this decreased mass transfer rate, as may be the case in the jar system. However, on further investigation it would appear that the holder which keeps the compact in place may be responsible for deflecting the upward flow. Also, as the metal used to construct the holder is $0.5 \mathrm{~mm}$ in diameter it is possible that this impedes the natural convection flow, as this diameter is of the same order of magnitude as the maximum concentration boundary layer thickness of such a flow. If this is the case, a better model for this system would be that of natural convection flow approaching a perpendicular surface, as discussed previously. Applying this model to the surface of a compact for volumetric flow rates of 8 , 16 and $43 \mathrm{~mL} / \mathrm{min}$ gives the results shown in table (7). These results are extremely close to the recorded ex-

Table 7 Predicted versus Experimental Dissolution Rates for a $13 \mathrm{~mm}$ benzoic acid compact in the Large flow through cell: Accounting for Effect of Tablet Holder

\begin{tabular}{ccc}
\hline $\begin{array}{c}\text { Volumetric } \\
\text { Flow Rate } \\
(\mathrm{mL} / \mathrm{min})\end{array}$ & $\begin{array}{c}\text { Predicted } \\
\text { Dissolution Rate } \\
(\mathrm{g} / \mathrm{s})\end{array}$ & $\begin{array}{c}\text { Experimental } \\
\text { Dissolution Rate } \\
(\mathrm{g} / \mathrm{s})\end{array}$ \\
\hline 0 & $2.958 \times 10^{-6}$ & $2.720 \times 10^{-6}$ \\
8 & $2.103 \times 10^{-6}$ & $2.078 \times 10^{-6}$ \\
16 & $2.104 \times 10^{-6}$ & $2.101 \times 10^{-6}$ \\
43 & $2.110 \times 10^{-6}$ & $2.255 \times 10^{-6}$ \\
\hline
\end{tabular}

2 Experiment performed in Free Convection Jar System. 
perimental values of D'Arcy et al[10]. However further experimental data is required to verify that the tablet holder has such an effect on the mass transfer rates from the surface of the compact.

\section{Discussion}

The primary aim of this research was to accurately predict drug dissolution rates from the vertical planar surface of a benzoic acid compact within the USP Flow Through Apparatus. In order to achieve this goal a number of factors had to be taken into consideration. These are discussed below and include, the interaction between natural and forced convection, the introduction of additional boundaries and the pulsating nature of the flow delivered by the pump.

\subsection{Natural vs Forced Convection}

The paper establishes that natural convection is the dominant mass transfer mechanism within the flowthrough cell. Firstly it is highlighted in section (3.1), table (1) that the downward velocity due to natural convection is in the order of $0.1 \mathrm{~cm} / \mathrm{s}$. In contrast, the pump delivering a volumetric flow rate of $16 \mathrm{ml} / \mathrm{min}$ through the large flow through cell would result in maximum upward velocities in the order of $0.065 \mathrm{~cm} / \mathrm{s}$.

Secondly, McDonnell[1] has shown that for such upward velocities, even neglecting the downward natural convection, the upward forced convection boundary layer would separate at very small distances from the leading edge due to the weight of solution containing dissolved drug. Furthermore, it is shown in section (3.3), table (4) that in order for forced convection to be considered the dominant mass transfer mechanism, the pump would be required to deliver volumetric flow rates well beyond normal operating conditions.

In summary, the paper shows three distinct cases. For small upward velocities, the upward flow does not penetrate the natural convection boundary layer and instead flows around it, having a decelerating effect on the natural convection flow. This supports the findings of several authors(D'Arcy et al[10], Cammarn and Sakr[11]), who report that an increase in pump flow rates did not always lead to an anticipated increase in dissolution rates.

The case of large velocities is of little interest in terms of dissolution rates as the required volumetric flow rates are unachievable within the flow through cell. However, the case is highlighted in $\operatorname{section}(3.3)$ in order to reaffirm the dominance of the natural convection process.
The most interesting cases are those involving intermediate velocities. For both flow through cells, these include volumetric flow rates of between 4 and $16 \mathrm{~mL} / \mathrm{min}$. These flow rates are indicative of normal operating conditions for the apparatus and result in regions of both natural and forced convection, as illustrated in figure (4).

Table (6) shows the initial results from applying these flow regimes to the surface of a compact in the Flow Through Apparatus at several volumetric flow rates. The results are somewhat disappointing except for the fact that they show little increase in dissolution rates for increased pump flow rates.

\subsection{Additional Boundaries}

As mentioned in section (1.3), the case for natural convection only is performed by D'Arcy et al $[8,9,10]$ in a so called Free Convection System. In this system the compact is adhered to the lid of a jar. The introduction of this extra boundary, namely the lid of the jar, may not be ignored. This Free Convection System is better modeled by natural convection flow developing at a stagnation point (McDonnell[2]) as outlined in section (2.3) of this paper.

In section (1.4) of this paper it is noted that the mathematical model used is analogous to that of Kuiken [12] in which the concentration boundary layer is an order of magnitude thinner than the momentum boundary layer. This thin concentration layer has a thickness of less than $0.5 \mathrm{~mm}$. Interestingly, the compact is held in position within the flow through cell by a tablet holder of diameter $0.5 \mathrm{~mm}$. The compact is held across its vertical planar surface and as such the introduction of this additional boundary may not be discounted. The tablet holder will inevitably cause boundary layer separation of the natural convection flow.

Table (7) presents an amended version of the results presented in table (6), allowing in each case for the introduction of additional boundaries as discussed above. The results presented in table (7) are extremely close to those of experiment and suggest that both the tablet holder and the jar lid have a dramatic effect on the dissolution rates from the surface.

\subsection{Constant vs Pulsing Flow}

Finally, it should be noted that in order to mathematically model the process of drug dissolution from the surface of a compact in the flow through cell, a constant time averaged velocity was taken as an approximation to the semi-sinusoidal velocity profile produced by the 
pump during experiments by D'Arcy et al $[8,9,10]$. This constant upward velocity may be viewed as the limiting case. That is to say, it would be unlikely for the semi-sinusoidal upward velocity produced by the pump to have a larger decelerating effect on the natural convection flow. In fact recent work by Yoshida et al[17] has shown that there was little difference observed in dissolution rates of salicylic acid in the large cell at the volumetric flow rates investigated for both the constant and semi-sinusoidal pulsating flow environments. This reaffirms the assumption that natural convection is the dominant mass transfer mechanism within the apparatus and that taking a time averaged upward velocity should have minimal effect on prediction errors.

\section{References}

1. D. McDonnell, B. Redmond and L.J. Crane, Mass Transfer from a Vertical Flat Plate due to Natural Convection with a Constant Counterflow, Zeitschrift fuer Angewandte Mathematik und Physik(ZAMP), 64, 1599-1607, (2013) DOI:10.1007/S00033-012-0298-5.

2. D. McDonnell,(2012). 'An Analysis of Drug Dissolution in Vivo'. Doctoral Thesis. Dublin Institute of Technology, Ireland. DOI: $10.21427 /$ D7T011

3. D. McDonnell, B. Redmond and L.J. Crane, Mass Transfer from a Vertical Flat Plate due to a Constant Upward Flow, Zeitschrift fr Angewandte Mathematik und Mechanik (ZAMM), 95(1), 111-116, 2015.

4. United States Pharmacopeia and National Formlary 39-NF34, The United States Pharmacopeial Convention, Rockville, MD, USA (2016).

5. E. Beyssac and J. Lavigne, Dissolution Study of Active Pharmaceutical Ingredients Using the Flow Through Apparatus USP 4, Dissolution Technologies, 12, 23-25, (2005).

6. I. Singh and H.Y. Aboul-Enein, Advantages of USP Apparatus IV (Flow-through Cell Apparatus) in Dissolution Studies, Journal of the Iranian Chemical Society, 3, page 220 (2006).

7. N. Fotaki, Flow-Through Cell Apparatus (USP Apparatus 4): Operation and Features, Dissolution Technologies, 18, 46-49, (2011).

8. D.M. D'Arcy, B. Liu and O.I. Corrigan, Investigating the effect of solubility and densitygradients on local hydrodynamics and drug dissolution in the USP 4 dissolution apparatus, International Journal of Pharmaceutics, Vol.419, page 175 (2011).

9. D.M. D'Arcy, B. Liu, G. Bradley, A.M. Healy and O.I. Corrigan, Hydrodynamic and Species Transfer Simulations in the USP 4 Dissolution Apparatus: Considerations for Dissolution in a Low Velocity Pulsing Flow, Pharmaceutical Research, 27, page 246 (2010).

10. D.M. D'Arcy, B. Liu, T. Persoons and O.I. Corrigan, Hydrodynamic Complexity Induced by the Pulsing Flow Field in the USP Dissolution Apparatus 4, Dissolution Technologies, 18, 6-13, (2011).

11. S.R. Cammarn and A. Sakr, Predicting dissolution via hydrodynamics: salicylic acid tablets in flow through cell dissolution, International Journal of Pharmaceutics, Vol.201, page 199 (2000).

12. H.M. Kuiken, An asymptotic solution for large Prandtl number free convection, Journal of Engineering Mathematics, 2, page 355 (1968).
13. H.B. Squire, 'Modern Developments in Fluid Dynamics' in S.Goldstein, Oxford University Press New York, (1938).

14. I. Tani, On the Solution of the Laminar Boundary Layer Equations, J. Phys. Soc. Japan, 4, page 149 (1949).

15. L. Howarth, On the Solution of the Laminar Boundary Layer Equations, Proc. Roy. Soc. London A, 164, page 547 (1938).

16. M.A. Lévêque, Les lois de la transmission de chaleur par convection, Ann Mines, 13, page 201 (1928).

17. H. Yoshida, A. Kuwana, H. Shibata, K. Izutsu and Y. Goda, Effects of Pump Pulsation on Hydrodynamic Properties and Dissolution Profiles in Flow-Through Dissolution Systems (USP 4), Pharm Res, 33, 1327 (2016). DOI:10.1007/s11095016-1874-8 